\title{
Cautious start for AAAS
}

\section{Washington}

The American Association for the Advancement of Science (AAAS), publisher of the journal Science, is to launch a new all-electronic rapid-publication journal tailored principally to the 'dataintensive' areas of science where conventional journals have difficulties in providing sufficient space.

Plans for the new journal, a joint venture between the AAAS and the Online Computer Library Center (OCLC) of Dublin, Ohio, were made public last week in a surprise announcement at the annual meeting of the AAAS in New Orleans. The new journal represents the first attempt by a major US scientific organization to offer electronic publication and may set a trend for the future. But Science is not about to vanish - the new journal will be a completely separate publication, even though planned in the same office.

Daniel E. Koshland Jr, editor of Science, says that a key advantage of the new journal will be in the amount of data that it can publish. "A lot of very good scientists do not send articles to Nature or Science because there is no way they can get enought data to be convincing in the size that we allow," says Koshland. The new journal will offer a new "intermediate" niche, part way between a conventional journal and a database.

The new journal will be referred in the same way as Science and "will require an editorial board," Koshland says, "that can decide, 'Yes that paper is at the right intermediate level of information'".

Papers that involve crystallographic coordinates and large amounts of sequence data (where both Science and Nature will now often publish only the 'bits judged interesting', says Koshland) are obvious candidates for publication in electronic form, but they are not the only areas that the AAAS is thinking of.

Richard S. Nicholson, Executive Officer of AAAS and the man behind the deal with OCLC, says the new journal will be attractive in any area where readers want to have access to the data behind a manuscript and manipulate it for themselves.

Another appealing feature of the new journal is that a paper would be published - in the sense that it would be added to the journal's electronic archive - the instant that it had passed peer review. There will be no need for it to join a queue for space in an upcoming issue of the journal.

Access to the journal will be possible through electronic networks, but Koshland stresses that the availability of data in electronic form is the main attraction. $\mathrm{He}$ expects that many 'papers' will be submitted and sent out to referees and subscribers on disc.
For OCLC, AAAS's partner in the new journal, the joint venture is attractive because it will one day help libraries overcome storage and administration problems - electronic journals never need be sent away to the binders. OCLC is a non-profit computer library service and research organization, which was founded in 1967 by the university presidents of the state of Ohio. Since then it has grown into a network serving all 50 US states and 39 countries, offering computer services and access to the world's largest bibliographic database (containing 331 million location listings) to over 10,000 libraries. In 1988 it dealt with an average of 2.6 million transactions a day, arranged over 4 million interlibrary loans, and took in revenues close to $\$ 100$ million.

According to OCLC spokesman Philip Schieber, the organization would like to move towards providing electronically not just standard bibliographic data (authors, titles, etccetera) but also data necessary for subject searches (a system is in experimental use) and eventually the full text itself. Over half of all library acquisitions are serials, he says, and libraries are keen to find innovative ways to deal with the growing costs of storing and subscribing to journals. Early involvement in an electronic journal is a logical step for OCLC in a competitive field in which "everybody is still just putting their toes in the water", says Schieber.

Nicholson is confident that publication of the journal can begin next year although many details have still to be worked out. Will the journal be able to accept advertising? Neither side in the joint venture is prepared to say. Advertising is possible some electronic newsletters force subscribers to give up several lines on their screens to a changing series of commercials. And how will subscribers pay for the journal? Will there be a fixed subscription or will users pay according to how much they wish to see? Nicholson says that many possibilities are under consideration.

Elsewhere, schemes with similar objectives or using similar methods are at a similar stage of development. In Europe, for example, a consortium of Elsevier, Springer, Pergamon and Blackwells, all major journals publishers, are believed to be on the point of selling packages of information based on the contents of existing journals, but in electronic form.

Nature, with which Science is often compared, has for some months suggested to the authors of papers accompanied by large amounts of data that this should be circulated separately as "supplementary information", with the intention that this should eventually be available electronically.

Alun Anderson

\section{'KGB hackers' get off lightly}

\section{Celle, West Germany}

THREE West Germans found guilty of breaking into US federal computers and selling information to the KGB, the Soviet intelligence agency, received relatively mild punishment last month from a West German court because of the incompetence of their attempt at espionage. The men were given sentences of fourteen months to two years but were released on probation for three years. They were also required to pay a fine of DM18,000, a fraction of the DM $90,000(\$ 54,000)$ they received from the KGB. The prosecutor, Max-Ekkehard Kohlhaas of the Federal Prosecutor's Office, had requested a longer jail term for one of the defendants, Peter Carl, because he had been the most important link to the KGB.

The sentence was light, the court explained, because little damage had been done. "What the defendants offered did not interest the Russians", said the chief judge, Leopold Spiller, "and the defendants did not gain access to anything very interesting." Two of the sentenced hackers, along with a third, Karl Koch, who died in mysterious circumstances in May 1989 , had offered to sell the KGB everything they knew for DM1 million, but the KGB turned them down.

The attempted spying was unearthed by US astronomer Clifford Stoll, who discovered in 1986 that hackers had broken into the computer at Lawrence Berkeley Laboratories (LBL) in California, and were trying to gain access from there to hundreds of computer systems at military bases and research institutes (see Nature 333, 105; 1988). The hackers admitted to having had dealings with the KGB but denied that they had been tracked by Stoll. They apparently convinced the court of that, because Stoll admitted that other hackers had also been able to enter the LBL computer, and what might have been a test case for West German legislation against hacking therefore became an open-and-shut case on the more serious, but easier to prosecute charge of espionage.

Last week, the cabinet in Bonn created a new central authority to handle computer security. The Federal Office of Computer Security, which is attached to the Interior Ministry, will serve as a clearing house for data about computer misuse in industry and government. In the past, West Germany had only an office for protecting military computer security. The new office will help the computer industry and user community to develop strategies against misuse. It will also keep a closer watch on the West German telephone system, which was identified as a weak link in the US break-ins. 